\title{
INDEKS PLAK ANTARA GIGI BERJEJAL DENGAN GIGI TIDAK BERJEJAL SETELAH MENYIKAT GIGI PADA SISWA-SISWI SMP PAB 5 PATUMBAK TAHUN 2014
}

\author{
Asmawati $^{1}$, Adriana Hamsar ${ }^{2}$, Nurhamidah ${ }^{3}$ \\ Jurusan Keperawatan Gigi Poltekkes Kemenkes Medan
}

\begin{abstract}
Abstrak
Penyebab utama penyakit periodontal adalah plak. Plak gigi adalah deposit lunak yang melekat pada permukaan gigi dan terdiri atas mikroorganisme. Penelitian ini bertujuan untuk melihat ada tidaknya perbedaan indeks plak antara gigi berjejal dengan gigi tidak berjejal setelah menyikat gigi pada siswa-siswi SMP PAB 5 Patumbak. Jenis penelitian ini dilakukan adalah analitik dengan metode eksperimen semu dan rancangan yang digunakan adalah "pre test and post test only group design". Penelitian ini dilakukan dengan jumlah populasi 140 orang dan pengambilan sampel dilakukan pada siswa kelas 1 dan kelas 2 berjumlah 28 orang, yaitu 14 orang siswa/i yang memiliki gigi berjejal dan 14 orang siswa/i dengan gigi tidak berjejal. Dari hasil penelitian yang telah dilakukan diperoleh indeks plak rata-rata sampel gigi berjejal dan gigi tidak berjejal sebelum menyikat gigi dengan kategori baik yaitu $(0,74)$ dan $(0,87)$. Setelah dilakukan kegiatan menyikat gigi, rata-rata indeks plak siswa/i yang memiliki gigi berjejal maupun yang memiliki gigi tidak berjejal sama-sama dikategorikan baik yaitu 0,29 dan 0,36. Kesimpulan dari penelitian ini adalah tidak ada perbedaan indeks plak antara gigi berjejal dengan gigi tidak berjejal setelah menyikat gigi pada siswa-siswi SMP PAB 5 Patumbak.
\end{abstract}

Kata kunci: Indeks plak, gigi berjejal, gigi tidak berjejal

\section{PENDAHULUAN}

WHO bekerja sama dengan Federation of National Dental Assosiation (FDI) dan International Assosiation of Dental Research (IADR) membuat tujuan globalnya dengan slogan 'Global Goals for Oral Health 2020‘.Tujuannya adalah untuk mengurangi penyakit gigi dan mengurangi dampaknya terhadap kesehatan dan perkembangan psikososial, dengan menekankan pentingnya kesehatan rongga mulut. Selain itu, mengurangi dampak manifestasi penyakit sistemik di rongga mulut pada seseorang dan memanfaatkan manifestasi ini untuk melakukan deteksi dini dan pencegahan serta penatalaksanaan penyakit sistemik. (WHO, 2003).

Plak merupakan penyebab lokal dan utama terbentuknya penyakit gigi dan mulut yang lain seperti karies gigi (lubang gigi), kalkulus (karang gigi), gingivitis (radang pada gusi), periodontitis atau radang pada jaringan penyangga ggi. (Megananda, dkk. 2009). Gigi berjejal disebabkan oleh banyak faktor seperti gigi susu yang terlambat dicabut padahal gigi tetapnya sudah tumbuh. Bisa juga karena gigi susu dicabut sebelum waktunya, adanya gigi gigi berlebihan sehingga dapat menghalangi terjadinya oklusi normal.

Kondisi dimana gigi berjejal merupakan salah satu faktor terjadinya penumpukan plak pada gigi. Sisa makanan yang menyangkut pada gigi yang berjejal mengakibatkan sulitnya saliva membersihkan sisa makanan tersebut. Apabila penyikatan gigi tidak dilakukan dengan baik dan benar maka sisa makanan tersebut mengakibatkan terjadinya penumpukan plak. (Yowono, L., 2010)

Setelah mengetahui bahwa gigi berjejal dapat menyebabkan penumpukan plak pada gigi sulit dibersihkan karena tidak terjangkau ketika menyikat gigi. Hasil survey awal diketahui bahwa pada siswa/i SMP PAB 5 Patumbak sebanyak 20\% ditemukan siswa yang mempunyai gigi berjejal. Sehingga, peneliti tertarik untuk melihat perbedaan indeks plak antara siswa/i yang mempunyai gigi yang berjejal dengan gigi yang tidak berjejal setelah menyikat gigi.

\section{Tujuan Penelitian}

Untuk mengetahui perbedaan indeks plak antara gigi berjejal dengan gigi tidak berjejal setelah menyikat gigi.

\section{Manfaat Penelitian}

1. Menambah wawasan pengetahuan siswa-siswi bahwa gigi berjejal menyebabkan tumpukan plak yang sulit dibersihkan karena ada bagian gigi yang sulit dijangkau oleh sikat gigi

2. Sebagai informasi dan bahan masukan bagi pihak sekolah tentang bahwa gigi berjejal lebih sulit dibersihkan daripada gigi yang tidak berjejal sehingga perlu ketelitian yang lebih untuk membersihkannya dan sebisa mungkin dirawat jika sudah parah. 
3. Hasil penelitian ini diharapkan sebagai masukan bagi peneliti lain dan sebagai bahan referensi di perpustakaan Jurusan Keperawatan Gigi Poltekkes Kemenkes Medan.

\section{Hipotesis}

Ada perbedaan indeks plak antara gigi berjejal dengan gigi tidak berjejal setelah menyikat gigi.

\section{METODE PENELITIAN}

\section{Jenis Dan Desain Penelitian}

Jenis penelitian yang di gunakan adalah eksperimen dengan rancangan pre test and post test only group design, yang bertujuan untuk mengetahui apakah ada perbedaan indeks plak antara gigi berjejal dan gigi tidak berjejal pada siswa-siswi SMP PAB 5 Patumbak.

\section{Populasi dan sampel penelitian}

Populasi dalam penelitian ini adalah seluruh siswa siswi SMP PAB 5 Patumbak tahun 2014. Jumlah populasi dalam penelitian ini berjumlah 140 orang.

Sampel penelitian ini adalah berjumlah 28 orang, siswa-siswi SMP PAB 5 Patumbak (20\% dari populasi).

\section{HASIL DAN PEMBAHASAN}

\section{Hasil Penelitian}

\subsection{Analisa Univariat}

Analisa data secara univariat dilakukan untuk mendapatkan gambaran distribusi frekuensi responden. Analisa ini digunakan untuk memperoleh gambaran masing-masing Variabel independent (bebas) yaitu ratarata indeks plak gigi berjejal sebelum menyikat gigi.

Tabel 1 Distribusi frekuensi indeks plak gigi berjejal sebelum menyikat gigi pada siswa-siwi SMP PAB 5 Patumbak Tahun 2014.

\begin{tabular}{ccc}
\hline Kriteria & Jumlah siswa & Jumlah indeks plak \\
\hline Baik & 11 & 7,11 \\
Sedang & 3 & 3,24 \\
Buruk & 0 & 0 \\
\hline Jumlah & 14 & 10,35 \\
Rata-rata indeks plak & & 0,74 \\
\hline
\end{tabular}

Dari tabel distribusi frekuensi diatas, dapat diketahui bahwa bahwa rata-rata skor indeks plak siswa/i gigi berjejal sebelum menyikat gigi di SMP PAB 5 Patumbak adalah 0,74 (Kriteria baik).

Tabel 2 Distribusi frekuensi indeks plak gigi berjejal setelah menyikat gigi pada siswa-siwi SMP PAB 5 Patumbak Tahun 2014

\begin{tabular}{ccc}
\hline Kriteria & Jumlah Siswa Jumlah Indeks Plak \\
\hline Baik & 14 & 4,06 \\
Sedang & 0 & 0 \\
Buruk & 0 & 0 \\
\hline Jumlah & 14 & 4,06 \\
Rata-rata indeks plak & & 0,29 \\
\hline
\end{tabular}

Berdasarkan tabel distribusi frekuensi diatas, dapat diketahui bahwa dari 14 siswa-siswi SMP PAB 5 Patumbak tahun 2014 rata-rata indeks plak gigi berjejal setelah menyikat gigi adalah 0,29 (kriteria baik)

Tabel 3. Distribusi frekuensi indeks plak gigi tidak berjejal sebelum menyikat gigi pada siswa-siwi SMP PAB 5 Patumbak Tahun 2014.

\begin{tabular}{ccc}
\hline Kriteria & Jumlah siswa & Jumlah indeks plak \\
\hline Baik & 10 & 7,05 \\
Sedang & 4 & 5,2 \\
Buruk & 0 & 0 \\
\hline Jumlah & 14 & 12,25 \\
Rata-rata indeks plak & & 0,87 \\
\hline
\end{tabular}

Dari tabel distribusi frekuensi diatas, dapat diketahui bahwa bahwa rata-rata skor indeks plak siswasiswi gigi tidak berjejal sebelum menyikat gigi di SMP PAB 5 Patumbak adalah 0,87 (Kriteria baik).

Tabel 4 Distribusi frekuensi indeks plak gigi tidak berjejal setelah menyikat gigi pada siswa-siwi SMP PAB 5 Patumbak Tahun 2014

\begin{tabular}{ccc}
\hline Kriteria & Jumlah Siswa & Jumlah Indeks Plak \\
\hline Baik & 13 & 3,84 \\
Sedang & 1 & 1,1 \\
Buruk & 0 & 0 \\
\hline Jumlah & 14 & 4,94 \\
Rata-rata indeks plak & & 0,36 \\
\hline
\end{tabular}

Berdasarkan tabel distribusi frekuensi diatas, dapat diketahui bahwa dari 14 siswa-siswi SMP PAB 5 Patumbak tahun 2014 rata-rata indeks plak gigi berjejal setelah menyikat gigi adalah 0,36 (kriteria baik)

\subsection{Analisa Bivariat}

Analisa bivariat berguna untuk mengetahui perbedaan indeks plak gigi berjejal dan tidak berjejal sebelum dan sesudah menyikat gigi tahun 2014 dengan menggunakan uji $t$.

Tabel 5 Perbedaan Indeks Plak Gigi Berjejal Sebelum dan Sesudah Menyikat Gigi pada siswa-siswi SMP PAB 5 Patumbak Tahun 2014

\begin{tabular}{cccccccc}
\hline $\begin{array}{c}\text { Mean Indeks } \\
\text { 'lak (Sebelum- } \begin{array}{c}\text { Karies } \\
\text { Setelah) }\end{array}\end{array}$ & Ada & \multicolumn{3}{c}{ tidak ada } & TOTAL & Sig $\boldsymbol{p}$ \\
\cline { 2 - 6 } & $\mathbf{F}$ & $\%$ & $\mathbf{F}$ & $\mathbf{\%}$ & $\mathbf{F}$ & $\mathbf{\%}$ & \\
\hline Melakukan & 5 & 12,5 & 11 & 27,5 & 16 & 40 & \\
& & & & & & & $\mathbf{0 , 0 0}$
\end{tabular}

$\begin{array}{lllllll}\text { Tidak } & 23 & 57,5 & 1 & 2,5 & 24 & 60\end{array}$

\begin{tabular}{cllllll} 
melakukan & & & & & & \\
\hline Total & 28 & 70 & 12 & 30 & 40 & 100 \\
\hline
\end{tabular}

\begin{tabular}{cccccc}
\hline $\begin{array}{c}\text { Mean Indeks Pli } \\
\text { (Sebelum- } \\
\text { Setelah) }\end{array}$ & N & $\mathrm{t}$ & Std & $\begin{array}{c}\text { Sig } \\
\text { (2Tailed) }\end{array}$ & $95 \%$ \\
\hline 0,21 & 14 & 1,88 & 0,42 & 0,08 & $0,03-0,4 \mathrm{t}$ \\
\hline
\end{tabular}


Berdasarkan tabel diatas menunjukkan hasil Pired Sample Test untuk gigi berjejal sebelum dan setelah menyikat gigi bahwa dari 28 orang siswa-siswi SMP PAB 5 Patumbak terdapat rata-rata 0,21 dengan nilai t hitung sebesar 1,88 .

Standart Deviasi yang diperoleh adalah 0,42 dengan signifikan (p) 0,08 dan menggunakan tingkat kepercayaan $95 \%$.

Dari hasil diatas terlihat bahwa t hitung adalah 1,88 dengan nilai $\mathrm{p} 0,08$. Oleh karena itu nilai $p>0,05$ artinya tidak ada perbedaan indeks plak antara gigi berjejal sebelum dan setelah menyikat gigi.

Tabel.6. Perbedaan Indeks Plak Gigi Tidak Berjejal Sebelum dan Setelah Menyikat Gigi Pada Siswa/i SMP PAB 5 Patumbak

\begin{tabular}{cccccc}
\hline $\begin{array}{c}\text { Mean Indeks } \\
\text { lak (Sebelum. } \\
\text { Setelah) }\end{array}$ & $\mathrm{N}$ & $\mathrm{t}$ & Std & $p$ & $95 \%$ \\
\hline 0,21 & 14 & 1,88 & 0,42 & 0,08 & $-0,03-0,41$ \\
\hline
\end{tabular}

Dari diatas menunjukkan hasil Pired Sample Test untuk gigi berjejal sebelum dan setelah menyikat gigi yaitu mean indeks plak sebelum dan setelah menyikat gigi pada gigi berjejal adalah 0,21 dengan jumlah sampel 28 orang dan menghasilkan nilai $t$ hitung sebesar 1,88. Standart Deviasi yang diperoleh adalah 0,42 dengan signifikan $(p)$ 0,08 dengan nilai $p 0,08(p>0,05)$ maka tidak ada perbedaan indeks plak antara gigi berjejal sebelum dan setelah menyikat gigi.

\section{Pembahasan}

Pada penelitian ini, peneliti ingin melihat ada tidaknya perbedaan indeks plak antara gigi berjejal dengan gigi tidak berjejal setelah menyikat gigi pada siswa-siswi SMP PAB 5 Patumbak. Penelitian ini mengambil sampel siswa-siswi yang mempunyai gigi berjejal sebanyak 14 orang dan siswa-siswi yang mempunyai gigi tidak berjejal sebanyak 14 orang yang dipilih mulai dari kelas 1 sampai kelas 2 SMP PAB 5 Patumbak.

Penyebab utama penyakit Periodontal adalah plak. Plak gigi adalah deposit lunak yang melekat pada permukaan gigi, terdiri atas mikroorganisme yang berkembang biak dalam suatu matrik interseluler jika seseorang melalaikan kebersihan gigi dan mulutnya. (Pintauli,dkk)

Gigi berjejal atau crowded disebabkan banyak faktor. Gigi berjejal bisa terjadi akibat gigi susu yang terlambat dicabut padahal gigi tetapnya sudah tumbuh. Bisa juga karena gigi susu dicabut sebelum waktunya. Akibatnya rahang kurang berkembang dan gigi tetap yang tumbuh kemudian kekurangan tempat untuk tumbuh dalam posisi normal.

Dari hasil penelitian ini program komputer dengan menggunakan uji t Dependent yang mencari ada tidaknya perbedaan indeks plak antara gigi berjejal dengan gigi tidak berjejal setelah menyikat gigi diperoleh hasil t hitung adalah 1,88 dengan nilai $\mathrm{p} 0,08$. Oleh karena itu nilai $\mathrm{p}>0,05$ maka $\mathrm{H} 0$ diterima artinya "tidak ada perbedaan indeks plak antara gigi berjejal sebelum dan setelah menyikat gigi".
Tidak adanya perbedaan indeks plak antar gigi berjejal dengan gigi tidak berjejal setelah menyikat gigi terjadi dikarenakan oleh tidak semua counfonding variabel (variabel pengganggu) dikendalikan. Variabel pengganggu yang dikendalikan hanya jenis sikat gigi dan pasta gigi sedangkan tehnik menyikat gigi dan lama menyikat gigi tidak dikendalikan.

Teori ini yang mendukung peneliti untuk tidak mengendalikan tehnik menyikat gigi dalam mencari ada tidaknya perbedaan indeks plak antara gigi berjejal dengan gigi tidak berjejal setelah menyikat gigi pada siswa/i SMP PAB 5 Patumbak. Hasil yang didapat dengan uji t Dependent dihasilkan bahwa tidak adanya perbedaan indeks plak antara gigi berjejal dengan gigi tidak berjejal setelah menyikat gigi pada siswa/i SMP PAB 5 Patumbak.

Walaupun hasil yang diperoleh tidak ada perbedaan indeks plak antara gigi berjejal dengan gigi tidak berjejal, bagi yang memiliki gigi berjejal harus lebih teliti untuk membersihkan giginya karena bagi gigi berjejal mempunyai peluang yang lebih besar untuk terjadinya penumpukan plak dikarenakan ada bagian-bagian gigi yang sulit dijangkau oleh sikat gigi. Dan bagi yang memiliki gigi tidak berjejal agar tidak mengabaikan kebersihan gigi dan mulutnya. Untuk memperoleh hasil pembersihan plak gigi yang optimal diharapkan agar menyikat gigi dengan cara yang baik dan benar.

Adapun manfaat yang dapat diambil dari penelitian ini adalah bahwa bagi yang memiliki gigi normal (tidak berjejal) untuk tidak mengabaikan kebersihan gigi dan mulutnya. Walaupun gigi tidak berjejal lebih mudah dibersihkan daripada gigi yang berjejal namun jika mengerti atau terampil dalam membersihkannya, maka tidak ada perbedaan dengan gigi berjejal yang memang terdapat kesulitan dalam membersihkannya karena ada bagian-bagian gigi yang tidak terjangkau oleh sikat gigi.

\section{SIMPULAN DAN SARAN}

\section{Simpulan}

1. Rata-rata indeks plak sebelum menyikat gigi pada gigi berjejal 0,74 (Baik) dan rata-rata indeks plak pada gigi tidak berjejal 0,87 (Baik). Setelah dilakukannya kegiatan menyikat gigi rata-rata indeks plak pada gigi berjejal sama-sama baik. Rata-rata indeks plak gigi berjejal 0,29 dan gigi tidak berjejal 0,36.

2. Hasil Dependent Sample Test menunjukkan bahwa tidak ada perbedaan indeks plak antara gigi berjejal dengan gigi tidak berjejal setelah menyikat gigi pada siswa-siswi SMP PAB 5 Patumbak.

\section{Saran}

Dari hasil penelitian yang telah dilakukan tentang perbedaan indeks plak antara gigi berjejal dengan gigi tidak berjejal setelah menyikat gigi disarankan: 
1. Gigi yang berjejal menyebabkan tumpukan plak yang ada sulit dibersihkan karena ada bagianbagian gigi yang sulit terjangkau oleh sikat gigi, oleh karena itu perlu ketelitian yang lebih dalam membersihkannya dan sebisa mungkin dirawat jika parah.

2. Menyikat gigi dengan cara yang baik dan benar agar memperoleh kebersihan gigi dan mulut yang optimal.

\section{DAFTAR PUSTAKA}

M. Sopiyudin Dahlan 2011. Statistik untuk kedokteran dan kesehatan. Jakarta: Salemba Medika

Pintauli, S., 2007. Menuju Gigi dan Mulut Sehat. USU Press. Medan.

Yuwono, L., 2007. Plak Gigi sumber penyakit Gigi dan Mulut, http://Lilliana Yuwono.wordpress.com/plak gigi/ diakses tanggal 20 desember.
Nurjannah N, 2012. Ilmu Pencegahan Penyakit Jaringan Keras dan Jaringan Pendukung Gigi, Penerbit Buku Kedokteran EGC, Jakarta.

Oral Health Promotion through Schools. WHO Information Series on School Health. Document 8. Geneva: WHO; 2003.

H P Megananda, Herijulianti E, Nurjanah N. 2009. Ilmu Pencegahan Penyakit Jaringan Keras dan Jaringan Pendukung Gigi. Buku Ajar. Poltekkes Depkes. JKG Bandung.

Erwin N, 2013. Seputar Kesehatan Gigi dan Mulut, Penerbit Rapha Publishing, Yogyakarta. 